\title{
Synthesis and Structural Reassignment of (+)-Epicalyxin F
}

\author{
Xia Tian and Scott D. Rychnovsky \\ Department of Chemistry, 1102 Natural Sciences II, University of California, Irvine, California \\ 92697-2025, srychnov@uci.edu
}

\section{Abstract}

We have established the structure of (+)-epicalyxin F through chemical synthesis. An acid promoted rearrangement of synthetic benzopyran 6 led to the identification of the natural product as $(3 S, 5 S$, $7 R$ )-epicalyxin F (22). Comparison with NMR spectra and optical rotation of the natural product confirms our assignment, and the reassigned structure is compatible with the proposed biosynthetic pathway.

The plant species Alpinia blepharocalyx is widely distributed in southwestern China and its seeds are commonly used in traditional medicine for the treatment of various stomach disorders. Kadota and coworkers reported the isolation of a family of related polyphenolic natural products from these seeds. ${ }^{1}$ We were drawn to the unique structure of (+)-epicalyxin $F(\mathbf{1})$ (the most biologically active member of the family) and its epimer (+)-calyxin F (2) (Figure 1). We synthesized the reported structure of epicalyxin F (1) through a Prins cyclization and FriedelCrafts cascade sequence. ${ }^{2,3}$ Unfortunately, data for our synthetic sample did not match that of the natural product. ${ }^{2}$ Subsequently, we discovered an acid mediated isomerization of compound $\mathbf{1}$ that led to the isolation of calyxin F. The proposed structure of calyxin F (2) was shown to be incorrect, and we reassigned calyxin $\mathrm{F}$ as structure $\mathbf{3}$ through spectroscopic studies and chemical correlation. ${ }^{2}$ However, the structure of our original target, epicalyxin F, remained a mystery.

We reasoned that calyxin $\mathrm{F}(\mathbf{3})$ and epicalyxin $\mathrm{F}$ had similar structures based on their very similar proton and carbon NMR spectra. Previously, we had synthesized 3-epi-calyxin F (4) and the methoxy regioisomer of calyxin $F(\mathbf{5})$ and shown that neither of these compounds matched the reported NMR data for epicalyxin F. ${ }^{2}$ The current project was initiated with the proposal that benzopyran 6 represented the true structure of epicalyxin F (Figure 1). We set out to synthesize compound $\mathbf{6}$ to test this hypothesis. Eventually we found that one of the assumptions underlying the hypothesis was incorrect, vide infra.

Our synthetic strategy (Figure 2) was designed to access the proposed epicalyxin F structure from three simple pieces, $\mathbf{8 , 9}$ and $\mathbf{1 0}$, that would be coupled together utilizing practical coupling reactions, namely the Mitsunobu reaction and olefin metathesis. Each of these components would be appropriately protected. An intramolecular Michael addition of enone 7 would close the remaining ring, and deprotection and ketone reduction would produce the target 6 .

The synthesis commenced with the preparation of triflate protected homoallylic alcohol 12 (Scheme 1). Keck allylation generated the homoallylic alcohol in good yield and high ee. 4 Enone 14 was prepared from known aldehyde $13^{5}$ by addition of vinylmagnesium bromide followed by oxidation. ${ }^{6}$ 
Preparation of the requisite chalcone derivative $\mathbf{1 7}$ began with commercially available narigenin 15 (Scheme 2). Two of the phenols could be selectively protected as THP ethers in the presence of the unreactive hydrogen-bonded phenol, which was subsequently methylated under standard conditions. The choice of THP as a protecting group generates multiple diastereomeric products, however, their ease of removal and low cost made them the ideal choice. ${ }^{7}$ Isomerization of the flavanone $\mathbf{1 6}$ to the open chalcone was accomplished under basic conditions. ${ }^{8}$ Deprotection followed by acylation of the more reactive phenols provided chalcone 17 in good overall yield. This synthesis established the correct methyl regioisomer and the requisite free phenol for the planned Mitsunobu reaction. The acetyl groups serve the dual role of protecting two of the phenols and enhancing the acidity of the free phenol.

With all three components in hand, we investigated their union to form the full carbon skeleton of the natural product (Scheme 3). Mitsunobu reaction between alcohol 12 and phenol 17 produced the ether 18 in excellent yield. Elimination of the benzyl alcohol was observed with related substrates, but the use of a triflate protecting group in $\mathbf{1 2}$ minimized this side reaction. Olefin cross-metathesis between 18 ( 1 equiv) and 14 ( 3 equiv) provided the desired intermediate $\mathbf{1 9}$ as a single alkene isomer without interference from the chalcone moiety. ${ }^{9}$, 10 Several catalysts were evaluated to promote the intramolecular conjugate addition that would form the final carbon-carbon bond in the target. $\mathrm{AuCl}_{3}$ and $\mathrm{BF}_{3} \cdot \mathrm{OEt}_{2}$ gave satisfactory yields of the product 20,11 however the selectivity at the newly formed methine carbon was low (2:1 and 1:1 respectively). The use of TMS-OTf gave a 67\% yield of the benzopyran 20 as a 5:1 mixture of diastereomers. ${ }^{12}$ The labile THP ether was cleaved by adventitious acid under the reaction conditions. This three-step sequence assembled the full skeleton of the target 6 with good selectivity and efficiency.

The synthesis was completed by a deprotection and reduction. Ketone $\mathbf{2 0}$ was treated with potassium methoxide in THF at ambient temperature to give the fully deprotected compound 21 in good yield. ${ }^{13}$ Sodium borohydride reduction gave an inseparable $4: 1$ mixture of diastereomeric alcohols 6 and 3-epi-6. Spectroscopic analysis of compound 6 and 3-epi-6 demonstrated that neither one corresponded to the natural product epicalyxin $\mathrm{F}$. The ${ }^{1} \mathrm{H} \mathrm{NMR}$ spectra were drastically different than that reported for epicalyxin F and did not match any of the known calyxin natural products. This outcome forced us to reevaluate the possible structure of epicalyxin F.

Upon close examination of the NMR data, we realized that the tabulated data for epicalyxin F did not match with the actual (unpublished) proton spectrum. ${ }^{14}$ Given the very similar spectra for calyxin $\mathrm{F}$ and epicalyxin $\mathrm{F}$, it was reasonable to propose that epicalyxin $\mathrm{F}$ was simply epimeric at the $\mathrm{C} 3$ position. Reexamination of the proton and carbon NMR data for the previously synthesized $(3 R, 5 R, 7 S)$-3-epi-calyxin $F(4)^{2}$ demonstrated that it matched epicalyxin $\mathrm{F}$. We were finally able to assign the relative configuration of epicalyxin $\mathrm{F}$ as that shown in structure 4

The absolute configuration of epicalyxin F was not known. Compound $\mathbf{4}$ had been prepared on a very small scale, and we did not have an optical rotation for comparison with the natural product. Fortunately, we could make use of our synthetic enone 6. Acid catalyzed isomerization of enone $\mathbf{6}$ to the benzopyran $\mathbf{2 2}$ had good precedent from our previous studies, ${ }^{2}$ and benzopyran 22 is the enantiomer of 4 . In the event, heating enone 6 in neat acetic acid at $90^{\circ}$ C for $12 \mathrm{~h}$ gave a $65 \%$ yield of benzopyran 22 (Scheme 4). The NMR data for compound 22 matched the unpublished spectrum for epicalyxin $\mathrm{F},{ }^{14}$ and the optical rotation was of the same sign. ${ }^{15}$ Thus the correct absolute configuration of natural epicalyxin $\mathrm{F}$ is $3 S, 5 S, 7 R$. Natural (+)-epicalyxn $\mathrm{F}$ is epimeric with natural (+)-calyxin $\mathrm{F}$ at the 5 and 7 positions, but both have the $S$-configuration at the $\mathrm{C} 3$ alcohol center. 
The biosynthetic pathway for the calyxin natural products as proposed by Kadota $1 \mathrm{a}$ is shown in Scheme 5. Reduction of the enone (23) followed by ionization of the allylic alcohol would generate an allylic cation that could be captured by chalcone $\mathbf{8}$ in a regioselective but not stereoselective manner to give two epimeric products (25). Subsequent protonation of the alkene produces a benzylic cation that can be attacked by the para-phenol or the free alcohol (the ortho-phenol is not nucleophilic due to hydrogen-bonding to the carbonyl of the chalcone). Closure onto the phenol would yield calyxin $\mathrm{F}$ and epicalyxin $\mathrm{F}$, and cyclization of the alcohol would form calyxin L. All three natural products have the same configuration at C3, as would be expected from this biosynthetic scheme.

A calyxin F regioisomer, enone 6, was proposed as a possible structure of epicalyxin F. Synthesis of enone $\mathbf{6}$ was accomplished in a highly convergent strategy from components $\mathbf{1 2}$, 14 and 17. Structure 6 did not correspond to epicalyxin F, but this work led to a reexamination of the data and the identification of the relative configuration of epicalyxin F. Ultimately enone 6 was shown to rearrange to epicalyxin $F$ on treatment with acid. The absolute configuration of (+)-epicalyxin F was assigned based on this concise synthesis of the natural product.

\section{Supplementary Material}

Refer to Web version on PubMed Central for supplementary material.

\section{Acknowledgements}

This work was supported by the National Cancer Institute (CA-081635) and by a generous donation from the Schering Plough Research Institute. We thank Professor S. Kadota (Toyama Medical and Pharmaceutical Univesity) for providing NMR spectra of calyxin $F$ and epicalyxin $F$.

\section{References}

1. a Prasain JK, Li JX, Tezuka Y, Tanaka K, Basnet P, Dong H, Namba T, Kadota S. J Chem Res. 1998 (S) 22-23, (M) 265-279 b Gewali MB, Tezuka Y, Banskota AH, Ali MS, Saiki I, Dong H, Kadota S. Org Lett 1999;1:1733-1736. [PubMed: 10836033] c Tezuka Y, Gewali MB, Ali MS, Banskota AH, Kadota S. J Nat Prod 2001;64:208-213. [PubMed: 11430002]

2. Tian X, Jaber JJ, Rychnovsky SD. J Org Chem 2006;71:3176-3183. [PubMed: 16599616]

3. For a related approach to 4-aryl THP rings, see: Yang XF, Wang M, Zhang Y, Li CJ. Synlett 2005:19121916.

4. The enantiomeric excess was determined by HPLC on a Chiracel OD-H column. Details may be found in the Supporting Information.

5. Bratt K, Sunnerheim K. J Chem Ecol 1999;25:2703-2714.

6. Parikh JR, Doering WvE. J Am Chem Soc 1967;89:5505-5507.

7. Use of MOM was problematic due to the harsh deprotection conditions required. TBS ethers were unstable to the methylation conditions. Acetate esters gave $C$-alkylation during methylation.

8. a Arcus VL, Simpson CD, Main L. J Chem Res 1992:80-81.(S) b Solladie G, Gehrold N, Maignan J. Eur J Org 1999:2303-2314. c Wang Y, Tan W, Li WZ, Li Y. J Nat Prod 2001;64:196-199. [PubMed: 11429999]

9. a Chatterjee AK, Choi TL, Sanders DP, Grubbs RH. J Am Chem Soc 2003;125:11360-11370.

[PubMed: 16220959] b Nicolaou KC, Bulger PG, Sarlah D. Angew Chem, Int Ed 2005;44:4490-4527. c Grubbs RH. Tetrahedron 2004;60:7117-7140.

10. Unreacted 18 was recovered in 30\% yield. The yield of $\mathbf{1 9}$ based on recovered 18 was $60 \%$.

11. Dyker G, Muth E, Hashmi ASK, Ding L. Adv Synth Catal 2003;345:1247-1252.

12. The mixture of isomers was separated by preparative HPLC to give pure cis isomer $\mathbf{2 0}$ for subsequent reactions.

13. Over time the ketone $\mathbf{2 0}$ isomerized to the cyclic hemiacetal by closure onto the phenol. Ketone $\mathbf{2 0}$ was characterized as the hemiacetal.

Org Lett. Author manuscript; available in PMC 2008 November 22. 
14. The doublet at $7.27 \mathrm{ppm}$ had been mistakenly tabulated as a doublet at $7.58 \mathrm{ppm}$, ref. $1 \mathrm{~b}$. Professor Kadota kindly provided copies of the original spectral data.

15. The optical rotation of $\mathbf{2 2}$ was of the same sign but there is a discrepancy in the magnitude: $(\alpha]^{25} \mathrm{D}$ $=+13.2(c 0.20, \mathrm{MeOH})$; lit. $($ ref $1 \mathrm{~b}):[\alpha]^{25} \mathrm{D}=+103.1(c 0.05, \mathrm{MeOH})$. Note that the rotation of synthetic calyxin $\mathrm{F}(3)$ is $[\alpha]_{\mathrm{D}}{ }^{25}=+16.3(c 0.175, \mathrm{MeOH})$, very much in accord with the magnitude of the rotation of synthetic epicalyxin $\mathrm{F}$. 


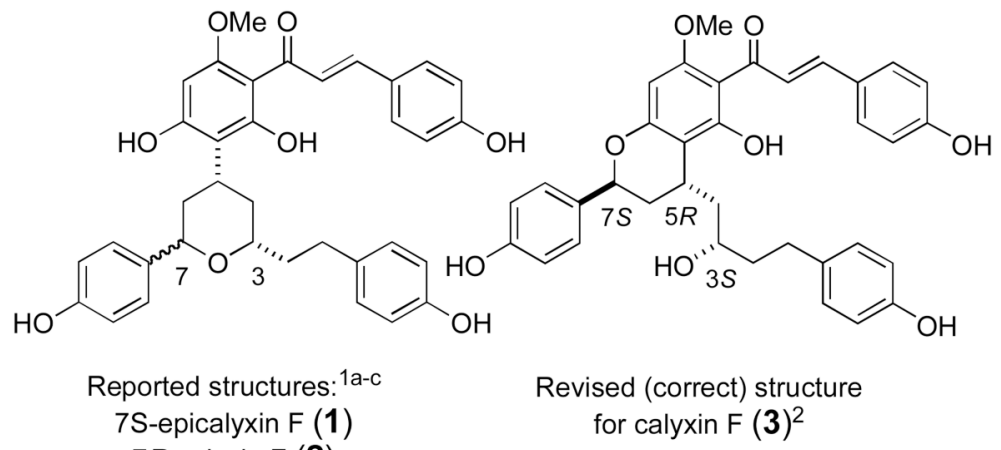<smiles>[R2]c1cc2c(c([R2])c1C(=O)/C=C/c1ccc(O)cc1)[C@@H](C[13C](O)CCc1ccc(O)cc1)C[C@@H](c1ccc(O)cc1)O2</smiles>

Previously discarded epicalyxin F structures: ${ }^{2}$ Proposed (incorrect) structure 3-epi structure 4: $\left(3 R, R^{1}=M e, R^{2}=H\right) \quad$ for epicalyxin $F(6)$ methoxy isomer 5 : $\left(3 S, \mathrm{R}^{1}=\mathrm{H}, \mathrm{R}^{2}=\mathrm{Me}\right)$

Figure 1.

Proposed structures of calyxin F and epicalyxin F. The correct structure for calyxin $\mathrm{F}$ is $\mathbf{3}{ }^{2}$ and the correct structure for epicalyxin $\mathrm{F}$ is given in the abstract (current work). 

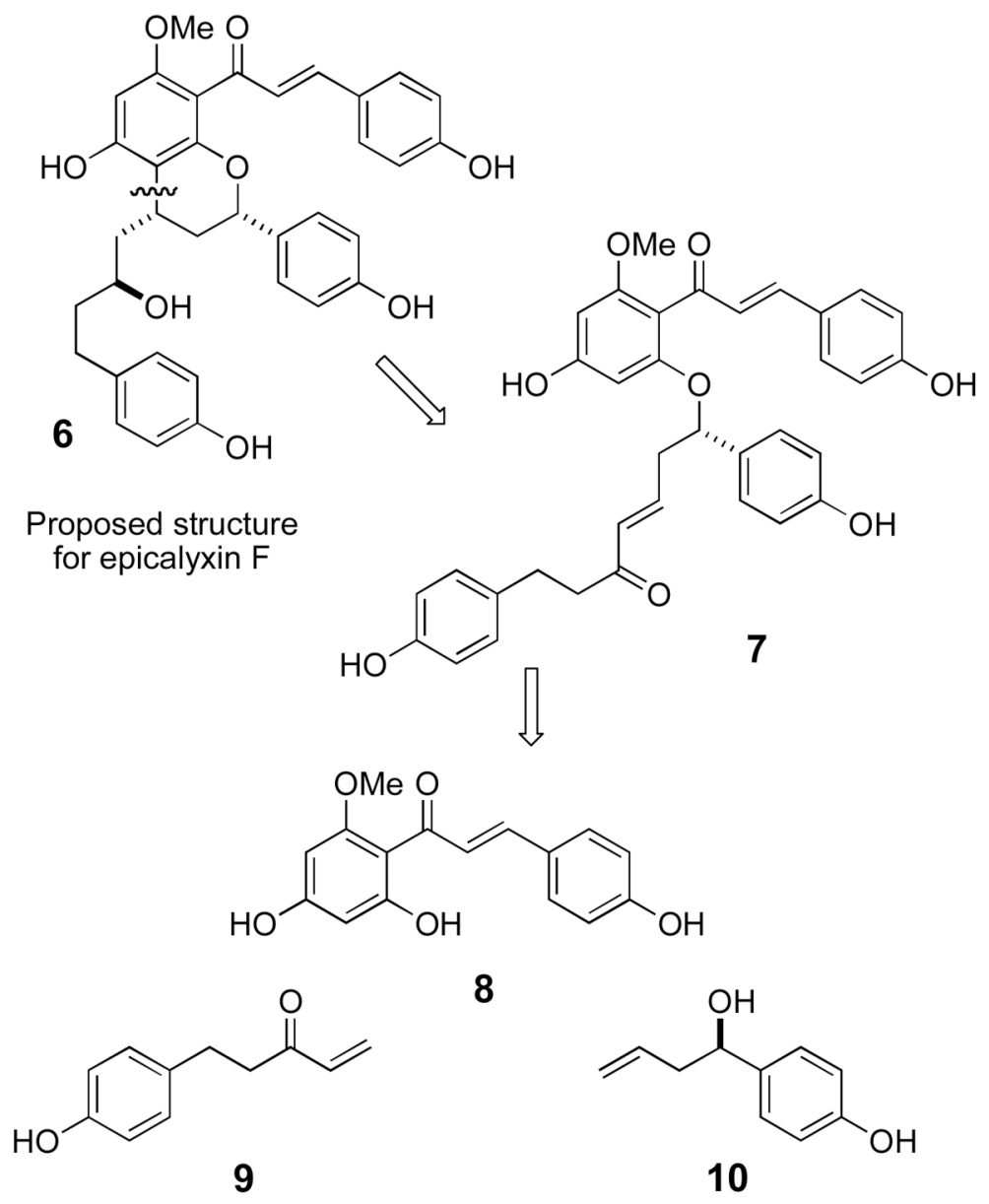

Figure 2.

Retrosynthetic Analysis of a Proposed Structure for Epicalyxin F (6) 
<smiles>O=Cc1ccc(O)cc1</smiles>

11
1) $\mathrm{Tf}_{2} \mathrm{O}$, pyridine

$0{ }^{\circ} \mathrm{C}, 86 \%$

2) $(R)-\mathrm{BINOL}, \mathrm{Ti}(\mathrm{O}-\mathrm{iPr})_{4}$

allyltributyltin

$\mathrm{CH}_{2} \mathrm{Cl}_{2},-20^{\circ} \mathrm{C}$

$87 \%, 95 \%$ ee

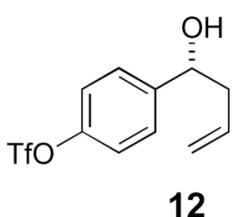

12

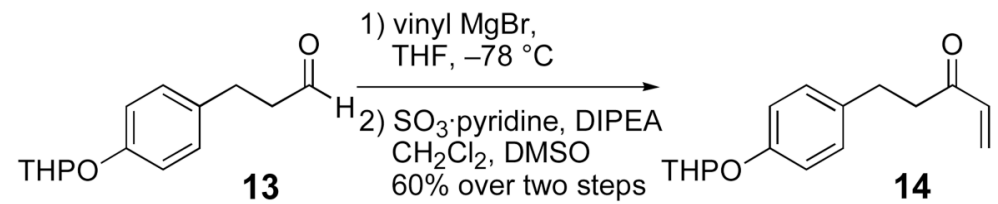

Scheme 1.

Synthesis of Alkene Fragments 

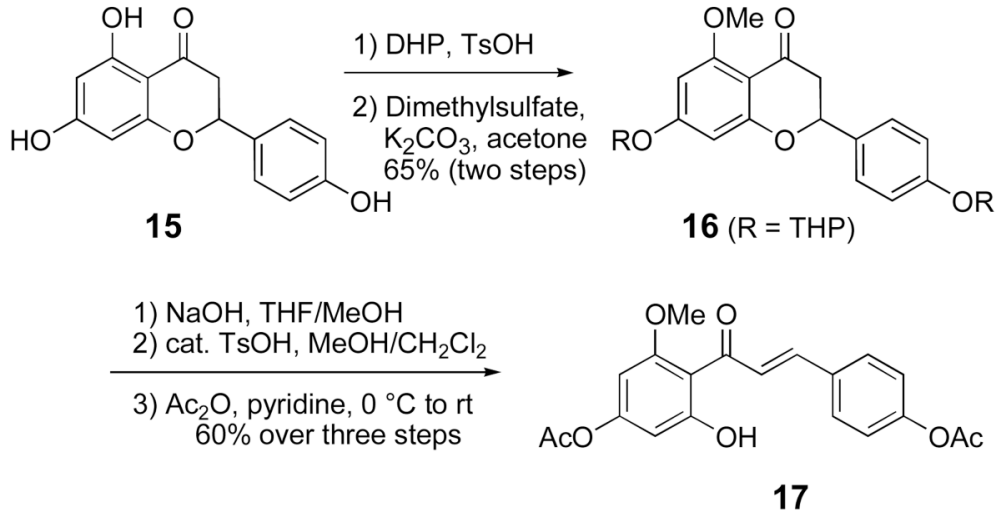

Scheme 2.

Synthesis of Chalcone Moiety 
<smiles>C=CCC(O)c1ccc(OC)cc1</smiles>

12 and<smiles>COc1cc(O)c(C(=O)/C=C/c2ccc(OC(C)=O)cc2)c(OC(C)=O)c1</smiles>

17<smiles>C=CCC(Oc1cc(OC(C)=O)cc(OC)c1C(=O)/C=C/c1ccc(OC(C)=O)cc1)c1ccc(O)cc1</smiles>

18

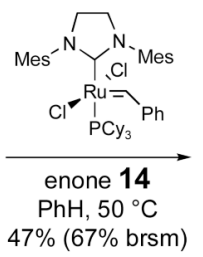

$47 \%$ (67\% brsm)<smiles>COc1cc(OC(C)=O)c(C(=O)/C=C/c2ccc(OC(C)=O)cc2)c(OC(C/C=C/C(=O)CCc2ccc([OH+])cc2)c2ccc(O)cc2)c1</smiles>

19<smiles>COc1cc(O)c2c(c1C(=O)/C=C/c1ccc(O)cc1)O[C@H](c1ccc(O)cc1)C[C@@H]2CC(=O)CCc1ccc(O)cc1</smiles>

21

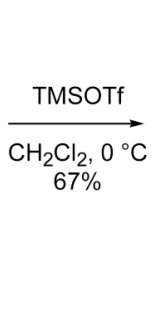

$\mathrm{HO}$

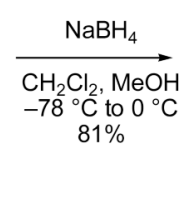

$\mathrm{HO}$<smiles>COc1cc(O)c2c(c1C(=O)/C=C/c1ccc(O)cc1)O[C@@H](c1ccc(O)cc1)C[C@@H]2CC(O)CCc1ccc(O)cc1</smiles>

Scheme 3.

Synthesis of the proposed epicalyxin F structure (6) 


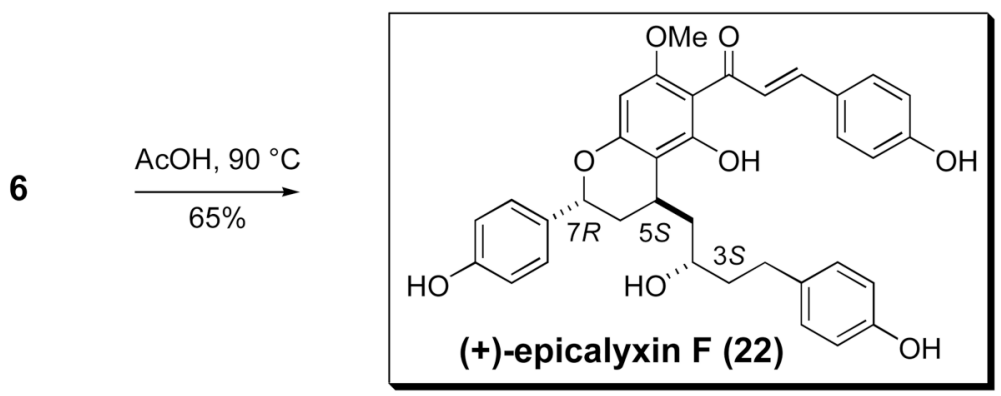

Scheme 4.

Rearrangement of Enone 6 to (+)-Epicalyxin F 

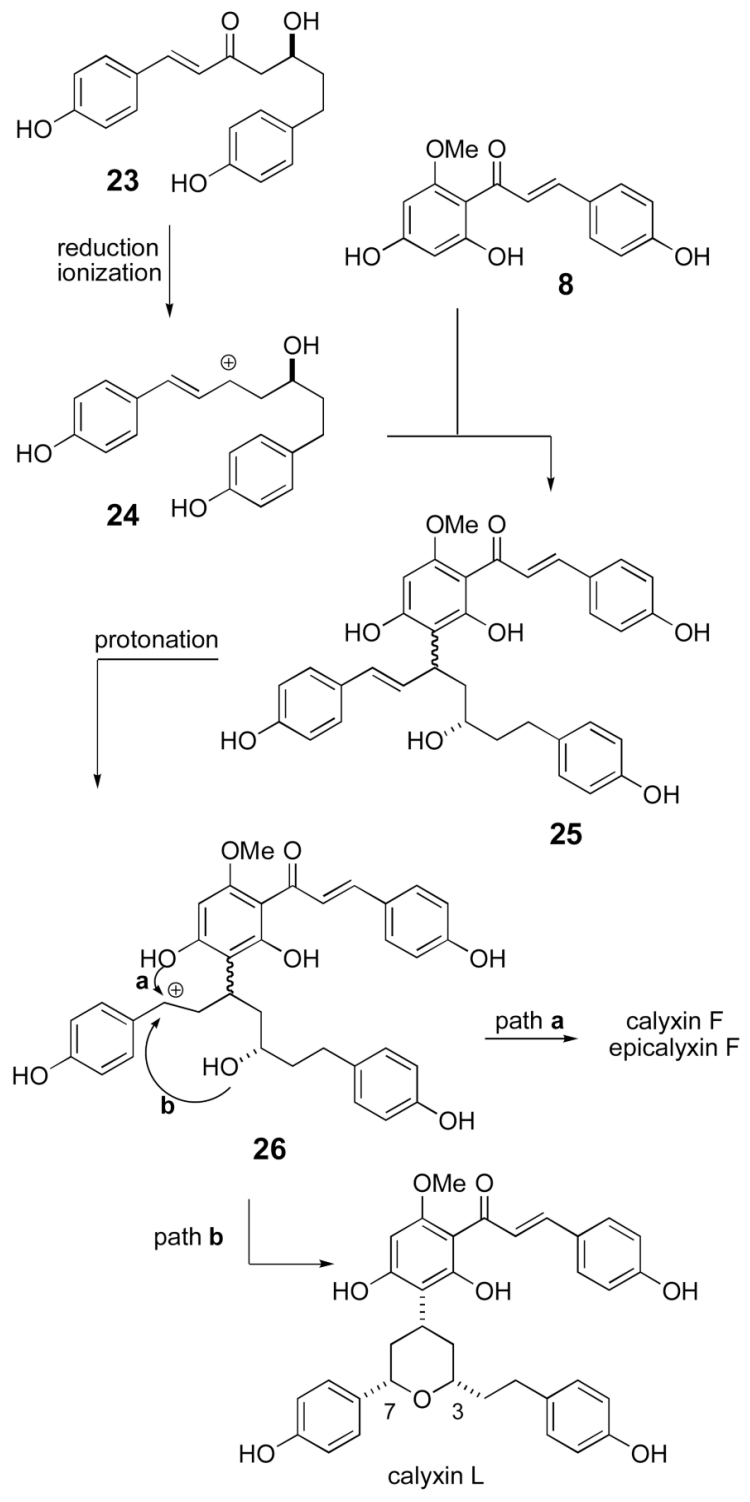

Scheme 5.

Proposed Biosynthesis of Several Calyxin Natural Products 